\title{
Correction to: Basiliximab versus rabbit antithymocyte globulin as induction therapy for living-related renal transplantation: a single-center experience
}

\author{
Hong-Feng Huang ${ }^{1,2,3,4}$. Jing-Yi Zhou ${ }^{1,2,3,4} \cdot$ Wen-Qing Xie ${ }^{1,2,3,4} \cdot$ Jian-Yong Wu $\mathbf{u}^{1,2,3,4} \cdot$ Hao Deng ${ }^{1,2,3,4}$. \\ Jiang-Hua Chen ${ }^{1,2,3,4}$
}

Published online: 21 January 2019

(c) Springer Nature B.V. 2019

\section{Correction to: Int Urol Nephrol (2016) 48:1363-1370 https://doi.org/10.1007/s11255-016-1307-y}

In the original publication, incorrect grant number was included in the Acknowledgements text as 'This study (article) was supported by Natural Science Foundation Y16H050011 of Zhejiang Province, China'. The correct acknowledgement section is given here.

Acknowledgement This study (article) was supported by Nature Science Foundation of Zhejiang Province (LY16H050003).

The original article can be found online at https://doi.org/10.1007/ s11255-016-1307-y.

Jiang-Hua Chen

chenjianghua@zju.edu.cn

1 Kidney Disease Center, The First Affiliated Hospital, College of Medicine, Zhejiang University, Qingchun Road 79, Hangzhou 310003, China

2 Key Laboratory of Nephropathy, Hangzhou, Zhejiang Province, China

3 Kidney Disease Immunology Laboratory, The Third Grade Laboratory, State Administration of Traditional Chinese Medicine of China, Hangzhou 310003, China

4 Key Laboratory of Multiple Organ Transplantation, Ministry of Health of China, Beijing, China 